\section{Rivalry target luminance does not affect suppression depth}

\section{MARK HOLLINS and GEORGE W. BAILEY University of North Carolina Chapel Hill, North Carolina 27514}

In 1955, Bouman introduced a technique of great potential for the measurement of binocular rivalry suppression. This was the presentation of a test flash superimposed on one of the rivaling targets. Bouman reported that threshold for the flash was higher when the target on which it fell was in the suppressed state than when it was in the dominant state, and that the difference between these two thresholds increased when the luminance of the contralateral eye's rivalry target increased.

Wales and Fox (1970) refined the increment threshold technique and stressed its importance for evaluating the depth of binocular rivalry suppression. It has since been shown with this method that the depth of rivalry suppression is independent of a variety of properties of the contralateral eye's rivalry target, such as its orientation (Blake \& Lema, 1978) and contrast (Blake \& Camisa, 1979). Makous and Sanders (1978) reported that dimming one of the rivalry targets had no effect on the depth of suppression, a finding that seems at odds with Bouman's (1955) observations.

Because Bouman's report stands alone on the question of the manipulability of suppression depth, we decided to explore the matter further. Like Bouman, we used colored targets and raised the luminance of the contralateral eye's target above that of the target seen by the eye receiving the flash. But we followed more recent studies in using both a forced-choice procedure to minimize criterion problems and gratings rather than uniform discs of light as rivalry targets. Because the flash durations used by Bouman (1955) and by Makous and Sanders (1978) were different (10 and $100 \mathrm{msec}$, respectively), we decided to carry out parallel measurements using both long and short flashes.

The experiments were performed on a five-channel Maxwellian-view optical system. Identical 8-deg backgrounds, containing a daylight filter and with a retinal illuminance of $2.7 \log \mathrm{Td}$, were presented continuously to the two eyes. A 5-min-diam black fixation dot was at the center of each background; a black ring and a pair of vertical lines were also present as aids to fusion (see Figure 1).

In addition, each eye viewed a 3-cycle/deg squarewave grating. The gratings were circular, with a diameter of $2 \mathrm{deg}$, and were centered on their backgrounds

This research was supported by NSF Grant BNS 77-23050.
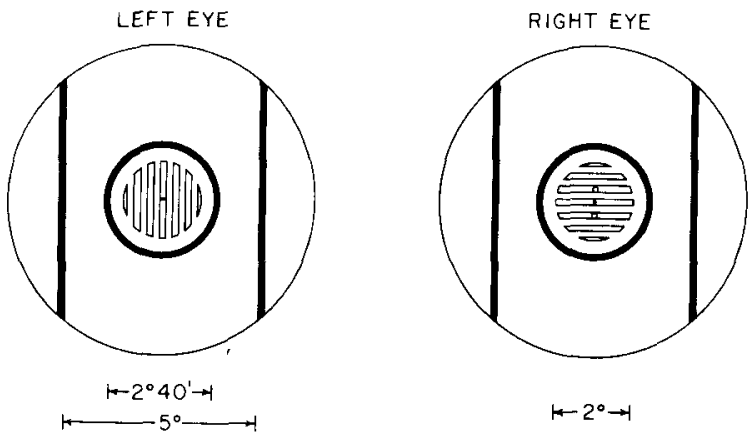

Figure 1. The stimulus array. The outer edge of the background and the heavy black contours served as fusion stimuli. The grating presented to the left eye was green $(522 \mathrm{~nm})$; that presented to the right eye was red $(680 \mathrm{~nm})$. The backgrounds and test flashes were white.

with even symmetry so that the fixation dot was at the center of a bright stripe. The left eye's grating was vertical; the right eye's was horizontal. The color of the gratings was controlled with blocked interference filters with a 10th-amplitude bandpass of about $14 \mathrm{~nm}$ and with peak wavelengths of $522 \mathrm{~nm}$ (left eye) and $680 \mathrm{~nm}$ (right eye). These high-contrast gratings, like the backgrounds, were produced photographically. The bright stripes in the right eye's grating had a retinal illuminance (not including the background) of $2.7 \log \mathrm{Td}$, making the space-averaged retinal illuminance of the grating $2.4 \log \mathrm{Td}$. This setting was about $1.2 \log$ units above threshold for the grating when it was viewed steadily against the background. The retinal illuminance of the left eye's grating was varied as described below.

Finally, a pair of test flashes was used in the right eye. These 10-min-diam white flashes were vertically aligned with the fixation point, from which they were separated by a center-to-center distance of $20 \mathrm{~min}$, with the result that each flash was centered within a bright bar of the horizontal grating. On a given trial, only one or the other of the flashes was presented. Inconel filters in each channel were used to control retinal illuminance; in addition, an inconel wedge driven by a stepping motor was used in the test flash channel. Small electromagnetic shutters were used to control presentation of flashes, which had onset and offset times of about $1.5 \mathrm{msec}$. All filament images in the pupil plane were less than $2 \mathrm{~mm}$ in diameter.

The course of the experiment was controlled with a PDP 11/03 computer, which operated the shutters, the stepping motor, and an auditory-signal beeper. In addition, the computer recorded the subject's responses on floppy disks for subsequent analysis.

The authors and a naive observer served as subjects. All had normal binocular vision. A dental impression bite bar and forehead rests were used to hold the sub- 
ject's head steady. Earphones were worn to exclude laboratory noises and to deliver tone signals to the subject.

A run began with $5 \mathrm{~min}$ of adaptation to the background, for the last $2 \mathrm{~min}$ of which the gratings were on as well. Following a "ready" signal coincident with the end of the adaptation period, the subject began recording the fluctuations of rivalry using the method of exclusive visibility (Hollins \& Leung, 1978). When only the left eye's grating was seen, the left end of a key was depressed; when only the right eye's grating was seen, the right end of the key was depressed; and when portions of both gratings were seen at once, the key was released and assumed a middle position.

At a suitable time, either th: upper or lower test flash, chosen randomly by the computer, was presented. Randomization was subject to no constraints. The subject, informed by a tone that a flash had occurred, was required to indicate, by depressing one of two pushbuttons, whether he believed it to be the upper or lower flash.

Five values of flash retinal illuminance, separated by $.2 \mathrm{log}$ unit and spanning a range found in preliminary measurements to include the subject's threshold, were used. Trials were arranged in blocks of 10 , within which each flash retinal illuminance was presented once during a period of left-eye dominance and once during a right-eye period. These 10 trials were presented in random order, with successive trials separated from one another by at least $10 \mathrm{sec}$. Flashes were always presented $500 \mathrm{msec}$ after the start of a period when only one grating or the other was seen. If the period ended less than $500 \mathrm{msec}$ after the start of the flash, that trial was automatically excluded from the analysis and was presented again (with the new position of the flash being chosen randomly) at the end of the block. The run ended after five such blocks were completed, and a break of at least $15 \mathrm{~min}$ was provided before the next run began.

Within a given run, test flash duration was either 20 or $100 \mathrm{msec}$. In addition, the retinal illuminance of the left eye's grating was equal to that of the right eye grating $(2.4 \log \mathrm{Td})$ in some runs and $.9 \log$ unit higher in other runs. There were thus four combinations of flash duration and left-eye-grating luminance. Runs under these four conditions were carried out in random order, subject to the constraint that no condition could be used a second time until all had been used once, and so on. Ten runs per condition were carried out on each subject.

To determine threshold values, frequency of seeing curves, with asymptotes set at $50 \%$ and $100 \%$ correct, were fit to the data using a least squares criterion. The fitting was done by the computer, using the binomial approximation to the normal ogive given by Lewis $(1966$, p. 221). The depth of suppression for a par-
Table 1

Depth of Suppression as a Function of Test Flash Duration and Retinal Illuminance of Left Eye Grating (log Td)

\begin{tabular}{|c|c|c|c|c|}
\hline \multirow[b]{2}{*}{ Subject } & \multicolumn{2}{|c|}{$20 \mathrm{Msec}$} & \multicolumn{2}{|c|}{$100 \mathrm{Msec}$} \\
\hline & 2.4 & 3.3 & 2.4 & 3.3 \\
\hline G.B. & .01 & .20 & .14 & .19 \\
\hline H.R. & .04 & .06 & .04 & .28 \\
\hline M.H. & .04 & -.03 & .03 & .15 \\
\hline
\end{tabular}

ticular condition was calculated by subtracting the mean (abscissa value for $75 \%$ correct) of the dominant-state ogive from the mean of the suppressed-state ogive. These values are given in Table 1 . It can be seen that the depth of suppression is surprisingly small. While 11 of the 12 entries in the table are positive, all are less than $.3 \log$ unit. The average value, $.1 \log$ unit, is considerably smaller than values encountered in the literature: .56 (the average depth of suppression found by Wales \& Fox, 1970), 3 (estimated by us from Figures 2, 3, and 4 of Makous \& Sanders, 1978), and .2 (our estimate from Figures 3, 4, and 5 of Blake \& Camisa, 1979).

While flash duration seems to have no consistent effect, there is a suggestion in the table that suppression depth is greater when the retinal illuminance of the grating presented to the contralateral eye is raised. We addressed the issue statistically in the following way. For each of the 10 runs per subject in each condition, frequencies of seeing curves were fit to the data and single-run estimates of the depth of suppression were determined. These values were then subjected to a twoway analysis of variance, with the data of each subject being considered separately. For no subject was the effect of left-eye-grating luminance or the effect of flash duration, or the interaction of these two factors, significant at the .05 level. There is thus no evidence that manipulation of our independent variables caused the variations seen in Table 1.

While the increment threshold technique was being employed to measure the depth of suppression, subjects were tracking their rivalry with a three-way switch, employing the method of exclusive visibility. Average amounts of exclusive visibility for the left and right eyes of each subject, under each experimental condition, are given in Table 2. Each of these entries is the percentage of time for which exclusive visibility occurred, averaged over runs.

In analyzing these measurements, we used a statistical approach similar to that employed in analyzing the data on depth of suppression: Analyses of variance were run separately on the data of each subject, with individual-run values of exclusive visibility making up the 10 replications per cell. For two of the subjects (G.B. and M.H.), exclusive visibility with the left eye dropped significantly $(p<.05)$ when retinal illuminance 
Table 2

Amount of Exclusive Visibility for the Left Eye (L) and the Right Eye (R), Expressed as a Percentage of Trial Duration, as a Function of Flash Duration and Retinal Illuminance of the Left Eye Grating $(\log T d)$

\begin{tabular}{|c|c|c|c|c|c|c|c|c|}
\hline \multirow{3}{*}{$\begin{array}{l}\text { Sub- } \\
\text { ject }\end{array}$} & \multicolumn{4}{|c|}{$20 \mathrm{Msec}$} & \multicolumn{4}{|c|}{$100 \mathrm{Msec}$} \\
\hline & \multicolumn{2}{|c|}{2.4} & \multicolumn{2}{|c|}{3.3} & \multicolumn{2}{|c|}{2.4} & \multicolumn{2}{|c|}{3.3} \\
\hline & L & $\mathbf{R}$ & $\mathrm{L}$ & $\mathrm{R}$ & L & $\mathbf{R}$ & $\mathrm{L}$ & $\mathbf{R}$ \\
\hline $\begin{array}{l}\text { G.B. } \\
\text { H.R. } \\
\text { M.H. }\end{array}$ & $\begin{array}{l}15.7 \\
28.2 \\
12.0\end{array}$ & $\begin{array}{l}21.6 \\
32.2 \\
15.5\end{array}$ & $\begin{array}{r}13.5 \\
26.6 \\
9.7\end{array}$ & $\begin{array}{r}18.3 \\
28.0 \\
9.5\end{array}$ & $\begin{array}{l}15.7 \\
25.4 \\
12.8\end{array}$ & $\begin{array}{l}21.0 \\
33.4 \\
15.6\end{array}$ & $\begin{array}{r}12.2 \\
27.8 \\
9.7\end{array}$ & $\begin{array}{r}18.1 \\
29.0 \\
8.7\end{array}$ \\
\hline
\end{tabular}

of the rivalry target presented to that eye was raised; the third subject showed no significant change in this measure. Less surprisingly, the increase in retinal illuminance of the left eye's grating also caused a decline in exclusive visibility for the right eye. This trend was significant in all subjects. Total exclusive visibility declined significantly in (the same) two of the three subjects. For no subject was the effect of flash duration or the interaction of flash duration and left-eye luminance significant.

Our finding that neither the retinal illuminance of the grating presented to the left eye nor the duration of the test flashes presented to the right exerted an influence on measurements of suppression depth supports the conclusion of earlier studies that the depth of suppression is independent of stimulus parameters (Blake \& Camisa, 1979; Blake \& Lema, 1978; Fox \& Check, 1968; Wales \& Fox, 1970; see also Makous \& Sanders, 1978). However, our results run counter to the report of Bouman (1955) that the depth of suppression increases with the luminance presented to the eye contralateral to that in which threshold is measured. The procedures in the two experiments differed in that Bouman used the classical method of constant stimuli, whereas we used a forced-choice procedure in which subjects were required to identify the location of the test flash. Moreover, during periods of right-eye suppression, Bouman measured the test-flash luminance required for "a breakdown of dominance of the nonmeasuring left eye and subsequent visibility of the flash" (p. 179), rather than that required simply for detection of the flash. This difference in criterion between his study and ours may have led to the difference in results.

The fact that depth of suppression did not vary with grating retinal illuminance in the present study, while exclusive visibility did, shows that the two techniques are not simply different ways of measuring a single underlying dimension of rivalry. The factors that establish the apparently constant depth of suppression are not the same ones that determine the time course of rivalry. This is the same conclusion reached by Blake and Camisa (1979), who varied the contrast rather than the luminance of their rivalry targets. If the depth of suppression is indeed invariant, then the acquisition of a more subtle understanding of rivalry is likely to require not only the continued use of tracking methods, but also the development of new psychophysical approaches.

\section{REFERENCES}

Blake, R., \& Camisa, J. On the inhibitory nature of binocular rivalry suppression. Journal of Experimental Psychology: Human Perception and Performance, 1979, 5, 315-323.

BLAKE, R., \& LEMA, S. A. Inhibitory effect of binocular rivalry suppression is independent of orientation. Vision Research, 1978, 18, 541-544.

Bouman, M. A. On foveal and peripheral interaction in binocular vision. Optica Acta, 1955, 1, 177-183.

Fox, R., \& Check, R. Detection of motion during binocular rivalry suppression. Journal of Experimental Psychology, 1968, 78, 388-395.

Hollins, M., \& Leung, E. H. L. The influence of color on binocular rivalry. In J. C. Armington, J. Krauskopf, \& B. R. Wooten (Eds.), Visual psychophysics and physiology. A volume dedicated to Lorrin Riggs. New York: Academic Press, 1978.

LEwIs, D. Quantitative methods in psychology. Iowa City: University of Iowa, 1966.

Makous, W., \& Sanders, R. K. Suppressive interaction between fused patterns. In J. C. Armington, J. Krauskopf, \& B. R. Wooten (Eds.), Visual psychophysics and physiology. A volume dedicated to Lorrin Riggs. New York: Academic Press, 1978.

WALES, R., \& Fox, R. Incremental detection thresholds during binocular rivalry suppression. Perception \& Psychophysics, $1970,8,90-94$.

(Manuscript received December 5, 1980; revision accepted for publication May 6, 1981.) 